Studia UBB 婿igitalia, Volume 65 (LXV) 2020, December, Issue 2, 49-56

Published Online: 2021-01-25

DOI: 10.24193/subbdigitalia.2020.2.04

\title{
Encoding youthful perspectives of the Anti-Communist Revolution
}

\author{
Maria Smaranda Rusu ${ }^{1}$
}

\begin{abstract}
Encoding youthful perspectives of the Anti-Communist Revolution" presents in a captivating manner two interviews dating back to the time in the history of Romania when the country was struggling with the Communist revolution which started in Timisoara. The perspective in which this information is described is the XML language. In order to simplify the data and to make it more accesible, there were used tags in a scheme. By using this method, the readers can have a better understanding of the text while having an over-all look upon the discussed historical issue.
\end{abstract}

Keywords: XML, Text encoding, Anti-Communist Revolution, Testimonies, Oxygen XML Editor

\section{Reasons for Choosing this Theme}

For this article, I have chosen the theme "Text encoding", and I have worked on texts concerning the 1989 Romanian revolution. I have managed to realize the project by using the XML Editor which is in my opinion, a very handy encoding language because it gives its users the chance to create any tag they desire, according to their own way of interpreting a text. By using the XML language I wanted to reveal how much easier the researchers task becomes when given the possibility to access a lot of data organized in a more compact yet smarter way. Let's take for example a text that is dense in information regarding many individuals and many more events. It would take a big amount of time to assimilate properly everything that the text has to offer. The XML Editor allows its user to arrange all the data in a more symmetrical way. The reader can access information about an event that is reffered in the text by simply moving the mouse cursor on the words containing the events name, making a tiny tab pop up. Even though, the tab will not contain as much data as a plain text, it

\footnotetext{
${ }^{1} 3^{\text {rd }}$ year BA student, Economics and Business Administration; maria smaranda17@yahoo.com.
} 
will sum up just enough to give the reader an idea about what happened during that event, giving him or her the opportunity to fully understand what they are reading about. If the reader will seek further information, he or she will know where to find it.

This paper is based on 2 testimonies given during the Anti-Communist Revolution in Timisoara, 1989. The two individuals that were interviewed narrate with their own words the events that took place between 16th and 17th of December 1989( the interviews can be found by visiting the website http://memoriatimisoarei.ro/ (last accessed 26.10.2020)and, the individuals that were interviewed are Botoc Cristina and Ardelean Gheorge; the journalist that interviewed them both is Onica Adrian).

One of the reasons for choosing this theme is the fact that the Communist Revolution served as a stepping stone for the evolution of Romania. It was a turn point that consisted of protests, fights between the civilians and the authorities, crossfires and many more actions that had devastating consequences upon the civilians caught in the middle of a political regime change.

I have chosen the XML language because its closely related to the HTML language which I would like to base my bachelor's degree on. Furthermore, XML is a metalanguage that has its own methods of use, methods that I would like to study more to become capable of defining my own markup tools.

$\mathrm{XML}$ is a markup language that defines a set of rules for encoding documents in a human-readable and computer-readable format. So what exactly is a markup language? Marking is the information added to a document that improves its meaning in certain ways, by identifying the parties and how they relate to each other. Specifically, a markup language is a set of symbols that can be placed in the text of a document to mark and label parts of that document.

XML has six important features that make it useful in a variety of systems and solutions:

- $\quad \mathrm{XML}$ is extensible;

- XML allows you to create your own self-descriptive or language tags that fit your application;

- XML carries the data, not presents it;

- XML allows you to store the data no matter how it will be presented;

- $\quad \mathrm{XML}$ is a public standard;

- XML was developed by an organization called the World Wide Web Consortium (W3C) and is available as an open standard.

This metalanguage helps me to enlarge my knowledge related to the computer field and at the same time, to be able to structure a text at first sight with more ease, to find different labels through which to divide a text much faster and to understand by methods for schematizing the content and use of data in a text.

Personally, I have chosen this topic due to the historical value of the testimonies and the ease of the mechanism of structuring some old texts with great significance, through XML, an application that offers an accurate character to the data 
in the online environment. This language fits perfectly with my way of thinking and interpreting a text, of any type.

\section{Data description}

I have done a detailed research in order to find information as old and authentic as possible.The source that gave me the most information was " http://www.memoriatimisoarei.ro/timisoara-povestita/povestiri-de-viata/remember-89--marturii-inregistrate-la-7-ani-de-la-revolutia-din-1989.html "(last accessed 26.10.2020). Here was able to find various interviews, taken by Adrian Onica on April 11, 1997, with individuals that played an active role in the Anti-Communist Revolution in Timisoara. Also, we found interviews with persons that had a family member involved in the atrocious event.

I have picked up the 2 interviews that moved me the most. The deep tragedy that came upon those involved and the atrocious consequences that followed leave us speechless.

The first interview is with Cristina BOTुOC. She lost her 13-year-old sister during $17^{\text {th }}$ of December when she left home with a group of children and never returned. Initially they looked for her at her friends place and then at the hospital where they found out that she was shot in the heart area. Later, by coincidence when looking for her at the morgue they found out that her autopsy had been done there. The search continued, until they came across the information that she was buried in the Heroes' Cemetery.

The second interview with Ardelean GHEORGHE, reveals us information about the vandalisation of the shops in Piata Operei, information regarding the crossfire from which he had initially escaped. When he joined another group of revolutionary he was shot in the leg and taken to the hospital. There, he was treated by doctor Barany and doctor Rădulescu, who also guided him not to tell the security guards that he participated in the Revolution. After recovering from his injuries, he returned home. Later, he began to attend hearings at the Prosecutor's Office where he was suggested constantly, that the army did not fire.

In order to structure these texts as well as possible, I've used the program Oxygen XML Editor and I have created multiple labels between paragraphs or words. After creating these labels, a schema can be generated.

Oxygen XML Editor is a program made for editing XML documents and also for validating the $\mathrm{XML}$ as it is entered. Usually, for additional schema types, a validation is generated and it allows Oxygen to use another programs to realize validation.

My goal was to create a schema as similar as possible for both texts.

Schemas can be viewed in four ways: text mode, grid mode, author mode and design mode.

So, after generating the schema I can see, from the Design mode, on the right side of the Palette screen, its components (what type of label I applied): a string, a group, an element, an attribute, a group of attributes, a complex or simple type. At the same time, I can see the composers and wildcards (sequence, choice, all, any, any 
attribute), but also the directives (import, inclusion, redefine) and constraints (key, key reference, unique, selector, field).

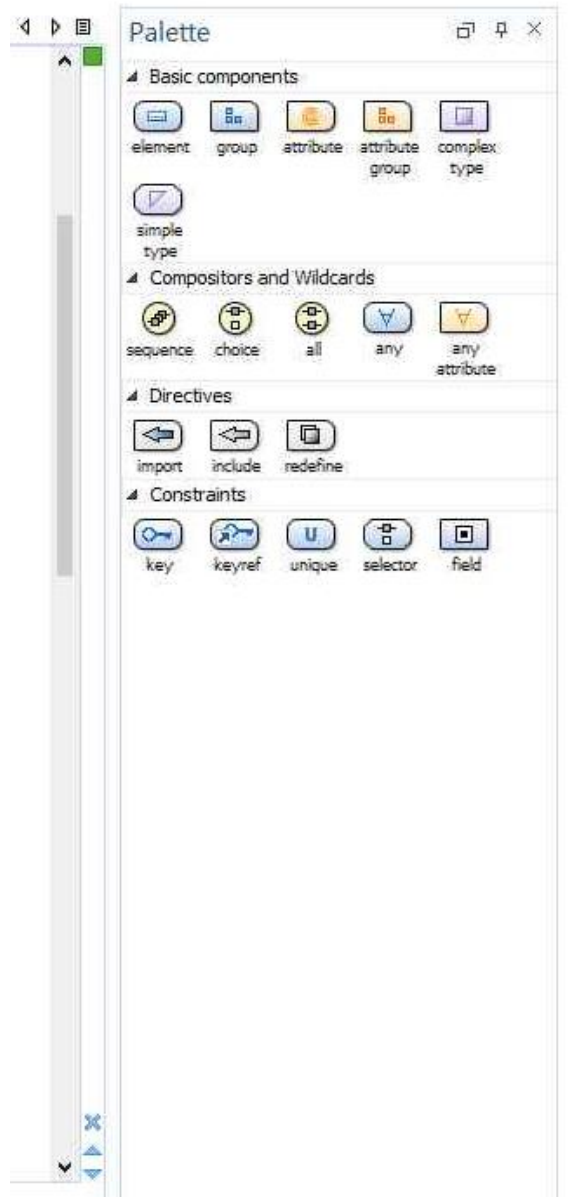

Fig.1. Oxygen XML Editor, Design Mode, Palette

In text mode, the schema can be viewed in code form, similar to the html language, the difference being the extensions at the beginning of the tags.

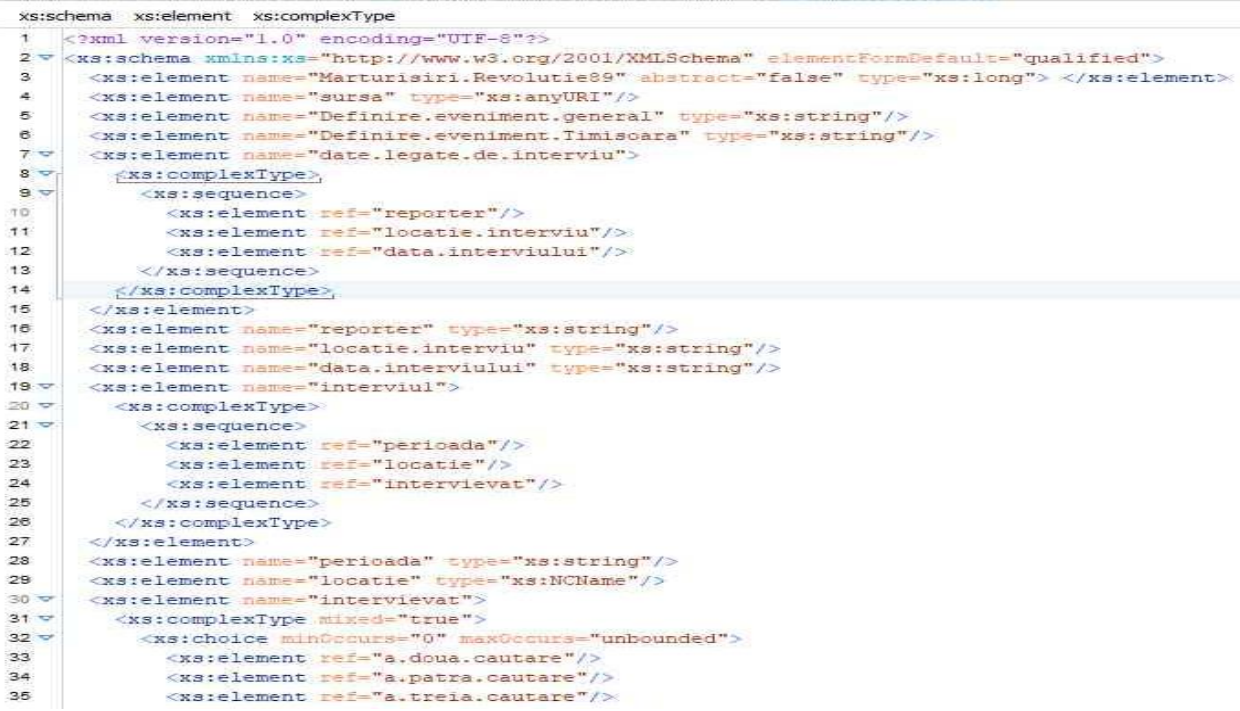

Fig.2. Oxygen XML Editor, Text Mode 
In Grid mode, the schema can be viewed as a table, and can be seen on the left, the title of the schema, the schema form, and its elements, and as columns are distinguished: name, whether the element is abstract or not, the type of element and if it is complex.

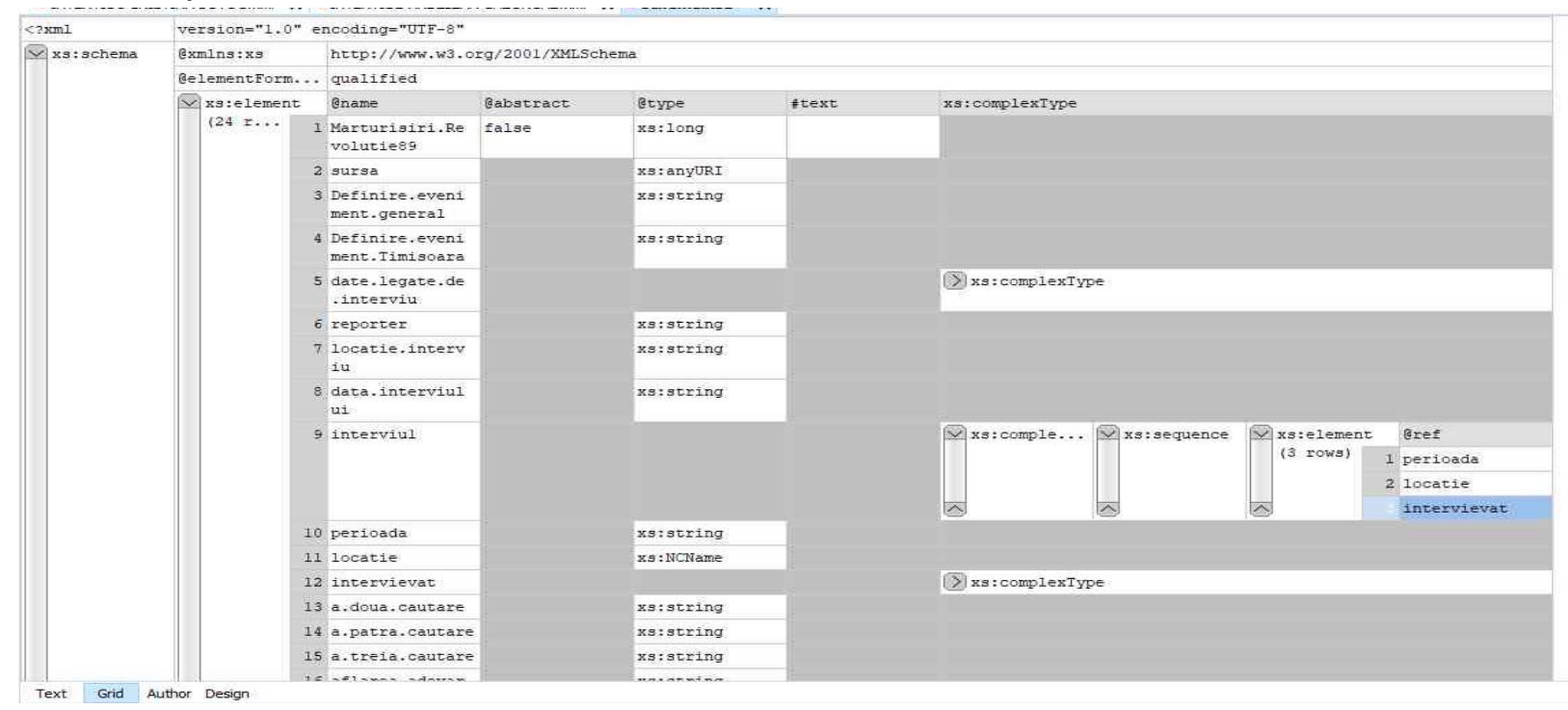

Fig.3. Oxygen XML Editor, Grid Mode

In Author mode, the schema can be viewed as a C / C ++ code. All the elements with their name and type appear.

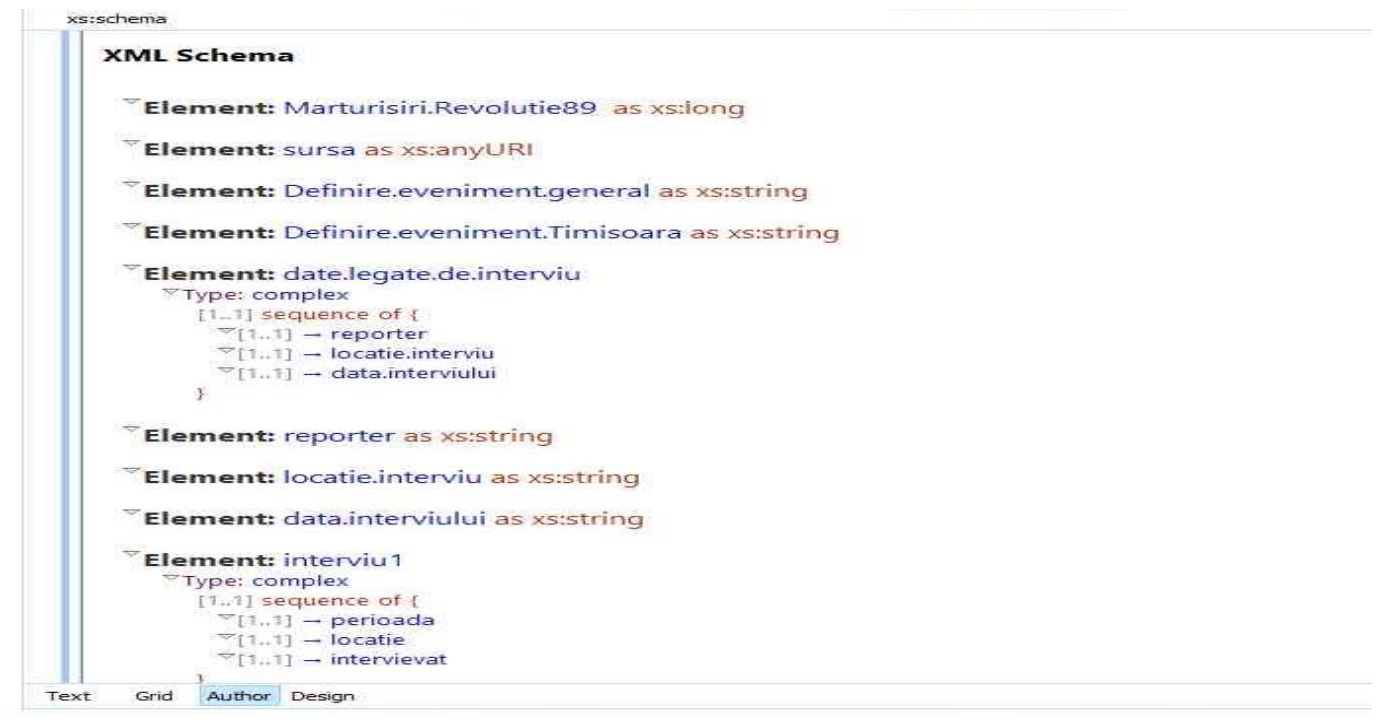

Fig.4. Oxygen XML Editor, Author Mode, XML Schema

\section{Project presentation}

After choosing the interviews, both based on the events of December 16-17, 1989 in Timisoara, I began to create the schema by adding as similar labels as possible. 
The first label is entitled "Confessions of Revolution 89" so that from the beginning I can frame the text in a historical context. All other labels that will follow are contained by.

In the following I will list and explain the labels used in the tag "Maturisiri Revolutie 89":

1. <Source>: Contains the URL link from where I extracted the interview. The site is entitled "Memory of Timisoara"

2. <General event definition>: Through this label I tried to place the reader in an authentic spacial-temporal framework, which presents in the foreground the revolution developed at national level.

3. <Defining the Timisoara event>: Through this label I tried to place the reader in an authentic spacial-teime framework, which presents in the foreground this revolution that took place in Timisoara.

4. <Interview data >: Within this label we have introduced others 3.

a. <reporter includes the name of the reporter

b. <interview location > includes the place where the interview took place

c. <date of interview> includes the date on which the interview was conducted

5. <interview > This tag is a more complex one because it contains the interview itself but also multiple other tags such as:

a. <period > Presents the period in which the action is described.

b. <location > Shows the location where the action is described.

c. <interviewee> This label contains all the information provided by the interviewee. Thus, it will contain some different labels due to the various stories of the interviewees.

I. The first interviewee "Cristina Boțoc"

- <interviewee name> Contains the name of the interviewee in this case Cristina Boțoc

- <interviewed status> Describes the place of birth, nationality, studies performed.

- <temporary placement of the action0> Commencement of the actual action, dating on December 17th, Sunday.

- <spatial placement>

- <event awareness> Represents Cristina's first interaction with the events that took place in front of the cinema. Which causes her to turn around and see what happens.

- $\quad$ <loss of sister> Presentation of the sister and her departure with another group of people that determined her final loss.

II. The second interviewee "Ardelean Gheorghe"

- <interviewee name> Contains the name of the interviewee in this case Ardelean Gheorghe

- <interviewed status> Describes the place of birth, nationality, studies performed and the job from the date of the interview. 
- <temporal placement of the action> The beginning of the actual action, the dating on December 16th, but also spatially through the label <spatial placement of the action $>$ which reflects the initial location of the action.

- <temporal placement of the action1> The label contains the date on which the action took place (December 17), but also the label <spatial placement of the action $>$ which places Ardelean G. in the Opera Square.

- <event awareness> Represents Gheorghe's first interaction with the events that took place in the Opera Square. The multitude of people present and the deeds committed by them, the theft and vandalism of the shops determined him to stay.

- <store vandalism> This label contains details about the vandalism of shops and buildings in the Opera Square by various young people

- <army attack1> Gheorghe hears the first series of gunfire

- <constining the gravity of the situation> The label contains: the paragraph in which Gheorghe realizes that everything is real and wants to leave, but also the label <the involvement of the army > the blocking of the streets by the military

- Escape from the military

- <army attack2> The label contains the initial when Gheorghe joined another group of demonstrators.

- <shooting by the army> The tag contains: information about the moment when Gheorghe was shot, but also the tag <reporter question>.

- <reporter question>

- <description of the wound> Shows information about the wound in the foot made by the shot.

- <arrival at the hospital> The demonstrators transported Gheorghe to the hospital, New, Emergency Clinics.

- <security interrogation> Contains the temporary placement label, dated December 19, but also the arrival of the security guards in the hospital. Patients were helped by doctors (this label <doctor's help>), who advised them to lie to the security guards about the cause of their injury.

- <hospital conditions> This section describes how patients were treated by doctors.

- <hiding the facts > Starting the hearings at the Prosecutor's Office, where the involvement of the army was denied

\section{Conclusions}

Following a search for Cristina Botoc's interview, another site that offers information is http://memoriatimisoarei.ro/ (last accessed 26.10.2020) which, although it provides the necessary information, structures it in the form of a journalistic article difficult to read in the online environment and more disadvantageously structured, vital information being difficult to find. 
In the case of the interview with Ardelean Gheorghe, the search for this interview on Google was inefficient, the results on the first page not being able to offer a platform for presenting the interview, while on the memoriatimisoarei.ro website it offers a search bar through which can reach the interview directly with him.

In conclusion, I considered that the use of the XML Editor program, in order to outline and label the two interviews on the events of the 1989 revolution against the communist regime was an effective method of simplifying, understanding and transposing historical information into a court with applicability in the online environment.

\section{References}

Gabriela A. (2019) 17 decembrie 1989. Nicolae Ceauşescu:

„Să lichidăm repede ce este în Timişoara”,

https://revolutions.mediafax.ro/personaje/17-decembrie-1989-nicolae-

ceausescu-sa-lichidam-repede-ce-este-in-timisoara-video-18668930

(Last

Accesed: 26.11.2020).

Redactie (2019) Noi nu uitam. Scanteia Revolutiei de la Timisoara se aprindea in 15

Decembrie 1989, in Piata Maria, https://www.opiniatimisoarei.ro/noi-nu-uitam-

scanteia-revolutiei-de-la-timisoara-se-aprindea-in-15-decembrie-1989-in-piata-

maria-4/15/12/2019 (Last Accessed: 26.11.2020).

Marius M. (2012) „Se Îngroaşă Gluma! Trebuie Să lasă Ceva!”, https://mariusmioc.wordpress.com/2012/08/24/se-ingroasa-gluma-trebuie-sa-

iasa-ceva/ (Accessed: 26.11.2020).

XML Tutorial (2006) https://www.tutorialspoint.com/xml/index.htm (Last Accesed: 26.11.2020).

Watt, Andrew H. (2002). Sams teach yourself XML in 10 minutes, https://en.wikipedia.org/wiki/Document type definition

(Last Accessed: 26.11.2020).

Liam Q. (2016) Extensible Markup Language (XML), https://www.w3.org/XML/ (Last Accessed: 26.11.2020). 